\title{
S.T. Fan: Living donor liver transplantation
}

\section{Takungpao Publishing Co. Ltd, China, 2007, 141 pages, 158 figures, format $21 \times 27 \mathrm{~cm}$, ISBN 962-582-115-5}

\author{
F. Duparc
}

Published online: 13 November 2008

(C) Springer-Verlag 2008

This book provides a personal overview of the living donor liver transplantation procedure in Hong Kong as an alternative to deceased donor liver transplantation.

The contributors are mainly liver surgeons and members of the liver transplantation team from The Queen Mary Hospital in the University of Hong Kong.

The book is divided into nine sections. The contents are listed in the beginning of the book and an useful index is provided at the end.

The first section is devoted to history of living donor liver transplantation in the world, than in Hong Kong, and the need to use this procedure in countries where deceased liver donation is absent.

In the second one, preoperative donor evaluation and management are explained in order to analyze the psychological and anatomical possibilities of performing the transplantation.

The following three sections, using high-quality illustrations, details the different liver grafts that can be used (left lateral bisegmentectomy, left hepatectomy or right hepatectomy). The sixth section focus on the problem of the median hepatic vein whose inclusion in the liver graft is still debated.

The three last sections analyze the complications of the procedures (biliary complications and small for size graft) and the results obtained in the author's series (about 300 procedures).

The aim of this book is to report a large experience of living donor liver transplantation. In a period of liver graft shortage associated with larger indications for liver transplantation, this book constitutes an excellent up-to-date review of our current knowledge of this procedure and can be recommended for all physicians dealing with this field of liver pathology.

Prof. Michel Scotté, MD, PhD

Digestive Surgery,

Rouen University Hospital,

France 